\title{
The Anticancer Efficacy of Plasma-Oxidized Saline (POS) in the Ehrlich Ascites Carcinoma Model In Vitro and In Vivo
}

\author{
Walison Augusto Silva Brito 1,2, Eric Freund 1,3 (D), Thiago Daniel Henrique do Nascimento ${ }^{2}$, \\ Gabriella Pasqual-Melo ${ }^{1}$, Larissa Juliani Sanches ${ }^{2}$, Joyce Hellen Ribeiro Dionísio ${ }^{2}$, William Capellari Fumegali ${ }^{2}$, \\ Lea Miebach ${ }^{1,3}$, Alessandra Lourenço Cecchini ${ }^{2,+}$ and Sander Bekeschus ${ }^{1, *,+}$ (i)
}

Citation: Brito, W.A.S.; Freund, E.; Nascimento, T.D.H.d.; Pasqual-Melo, G.; Sanches, L.J.; Dionísio, J.H.R.; Fumegali, W.C.; Miebach, L.; Cecchini, A.L.; Bekeschus, S. The Anticancer Efficacy of PlasmaOxidized Saline (POS) in the Ehrlich Ascites Carcinoma Model In Vitro and In Vivo. Biomedicines 2021, 9, 932. https://doi.org/10.3390/

biomedicines 9080932

Academic Editor: Gyoocheon Kim

Received: 17 June 2021

Accepted: 27 July 2021

Published: 31 July 2021

Publisher's Note: MDPI stays neutra with regard to jurisdictional claims in published maps and institutional affiliations.

Copyright: (c) 2021 by the authors. Licensee MDPI, Basel, Switzerland. This article is an open access article distributed under the terms and conditions of the Creative Commons Attribution (CC BY) license (https:// creativecommons.org/licenses/by/ $4.0 /)$

1 ZIK plasmatis, Leibniz Institute for Plasma Science and Technology (INP), Felix-Hausdorff-Str. 2, 17489 Greifswald, Germany; walison.brito@inp-greifswald.de (W.A.S.B.); eric.freund@inp-greifswald.de (E.F.); gabriella.pasqual-melo@inp-greifswald.de (G.P.-M.); lea.miebach@inp-greifswald.de (L.M.)

2 Department of General Pathology, State University of Londrina, Rodovia Celso Garcia Cid, Londrina 86051-990, Brazil; thiagohenrique_d_n@hotmail.com (T.D.H.d.N.); larisanches_89@hotmail.com (L.J.S.); joyce.ribeirod@gmail.com (J.H.R.D.); william.capellari@hotmail.com (W.C.F.); alcecchini@uel.br (A.L.C.)

3 Department of General, Visceral, Thoracic and Vascular Surgery, Sauerbruchstr. DZ7, Greifswald University Medical Center, 17475 Greifswald, Germany

* Correspondence: sander.bekeschus@inp-greifswald.de; +49-3834-554-3948

+ Contributed equally as last authors.

Abstract: Cold physical plasma, a partially ionized gas rich in reactive oxygen species (ROS), is receiving increasing interest as a novel anticancer agent via two modes. The first involves its application to cells and tissues directly, while the second uses physical plasma-derived ROS to oxidize liquids. Saline is a clinically accepted liquid, and here we explored the suitability of plasmaoxidized saline (POS) as anticancer agent technology in vitro and in vivo using the Ehrlich Ascites Carcinoma (EAC) model. EAC mainly grows as a suspension in the peritoneal cavity of mice, making this model ideally suited to test POS as a putative agent against peritoneal carcinomatosis frequently observed with colon, pancreas, and ovarium metastasis. Five POS injections led to a reduction of the tumor burden in vivo as well as in a decline of EAC cell growth and an arrest in metabolic activity ex vivo. The treatment was accompanied by a decreased antioxidant capacity of Ehrlich tumor cells and increased lipid oxidation in the ascites supernatants, while no other side effects were observed. Oxaliplatin and hydrogen peroxide were used as controls and mediated better and worse outcomes, respectively, with the former but not the latter inducing profound changes in the inflammatory milieu among 13 different cytokines investigated in ascites fluid. Modulation of inflammation in the POS group was modest but significant. These results promote POS as a promising candidate for targeting peritoneal carcinomatosis and malignant ascites and suggest EAC to be a suitable and convenient model for analyzing innovative POS approaches and combination therapies.

Keywords: cold physical plasma; EAC; kINPen; oncology; plasma medicine; ROS

\section{Introduction}

Despite global efforts, cancer continues to be a devastating disease, motivating new research lines for therapy. Especially tumors of the peritoneal cavity are frequently lethal, as these metastases provoke organ dysfunction and further systemic tumor dissemination [1] This is especially pronounced in colon, pancreatic, gastric, and ovarian cancer. Current strategies targeting peritoneal carcinomatosis (PC) involve peritoneal lavage with preheated liquids that contain tumor-toxic agents, a procedure called hyperthermal intraperitoneal chemotherapy (HIPEC), which often is combined with cytoreductive surgery [2]. HIPEC, however, often demonstrates severe side effects at appropriate to modest antitumor 
efficacy [3]. Combining HIPEC with other tumor-toxic agents might increase therapeutic efficacy while decreasing the chemotherapeutic concentration needed to elicit clinical responses. This, in turn, would also decrease side effects often observed by systemic dissemination of the chemotherapeutic agents provoked by the rapid uptake of the lavage fluid via the peritoneum.

Reactive oxygen species (ROS) have been proposed as a tumor-toxic modality for long because they often target different cell death-signaling modalities compared to anticancer drugs, provoking additive or even synergistic tumor-toxic effects [4]. However, ROS-producing modalities are limited to either single entities or treatment modalities that are complex to apply in the peritoneal cavity, such as photodynamic therapy. Recent technological leap innovations led to the emergence of a new anticancer modality, cold physical. This partially ionized gas is usually operated at body temperature and generates a plethora of ROS in the gas phase simultaneously, such as hydroxyl radicals, superoxide radicals, atomic oxygen, peroxynitrite, and singlet delta oxygen [5]. Applied in appropriate amounts, this physical modality is frequently reported to mediate tumor-toxic effects in several cancer models. Using, for instance, the kINPen plasma atmospheric pressure technology, we have provided evidence of direct anti-melanoma action in vitro [6], in vivo [7], and in clinical samples from stage IV melanoma patients ex vivo [8]. Interestingly, the complex ROS mixture of cold physical plasmas can also be applied to liquids, and these oxidized liquids can be subsequently used as a therapeutic modality. We have recently screened several types of clinically accredited liquids and identified $0.9 \%$ sodium chloride (saline) to be a suitable anticancer agent following exposure to cold physical plasma [9].

To explore the performance of kINPen argon plasma-oxidized saline (POS) as a putative anticancer agent, we used the Ehrlich Ascites Carcinoma (EAC) model and repeated intraperitoneal administration of POS for analyzing ascites cells and supernatants. We found POS to have a potent antitumor capacity while not inducing any side effects or overshooting inflammatory responses in the peritoneal cavity.

\section{Materials and Methods}

\subsection{Generation of Cold Physical Plasma-Oxidized Saline (POS)}

For generating plasma-oxidized saline (POS), $20 \mathrm{~mL}$ of clinical-grade isotonic sodium chloride solution ( $0.9 \%$ saline; Thermo Fisher Scientific, Bremen, Germany) was exposed to the gas plasma effluent of the atmospheric pressure plasma jet kINPen MED (neoplas MED, Greifswald, Germany) in a $50 \mathrm{~mL}$ glass beaker at a treatment distance of $20 \mathrm{~mm}$ as described previously [10]. The technical properties of the argon plasma jet have been outlined before [11]. As feed gas, argon gas (purity 99.999\%; Air Liquide, Paris, France) was used, running at five standard liters per minute. After the treatment time of $60 \mathrm{~min}$, evaporated liquid was compensated for using a predetermined amount of double-distilled water to re-establish iso-osmolarity within the POS. The solution was freshly prepared before each application.

\subsection{Analysis of Plasma-Oxidized Saline (POS)}

The $\mathrm{pH}$ level was measured using a calibrated $\mathrm{pH}$ meter (Mettler Toledo, Columbus, USA). Generation of hydrogen peroxide $\left(\mathrm{H}_{2} \mathrm{O}_{2}\right)$ in gas plasma oxidized saline was quantified using the Amplex Ultra Red assay (Thermo Fisher Scientific, Bremen, Germany) as described before [12]. The amount of nitrite $\left(\mathrm{NO}_{2}{ }^{-}\right)$and nitrate $\left(\mathrm{NO}_{3}{ }^{-}\right)$was determined using the Griess assay (Cayman Chemical, Ann Harbor, MI, USA) according to the manufacturer's instructions. Absorbance was measured at $540 \mathrm{~nm} 15 \mathrm{~min}$ after treatment using a multimode plate reader (F200; Tecan, Männedorf, Switzerland). The redox-sensitive probes 3'-(p-aminophenyl) fluorescein (APF; Thermo Fisher Scientific, Bremen, Germany) and 3'-(p-hydroxyphenyl) fluorescein (HPF; Thermo Fisher Scientific, Bremen, Germany) were used to analyze the generation of peroxynitrite $\left({ }^{-} \mathrm{ONOO}\right)$, hydroxyl radical $\left({ }^{\bullet} \mathrm{OH}\right)$ and / or hypochlorous acid $(\mathrm{HOCl})$. While both dyes can be oxidized by ${ }^{-} \mathrm{ONOO}$ and ${ }^{\bullet} \mathrm{OH}$, only APF is also sensitive to $\mathrm{HOCl}$ [13]. Both probes were added 
to POS at a concentration of $5 \mu \mathrm{M}$ after treatment. Fluorescence was acquired using a multiplate reader at $\lambda_{\mathrm{ex}} 485 \mathrm{~nm}$ and $\lambda_{\mathrm{em}} 535 \mathrm{~nm}$ (M200; Tecan, Männedorf, Switzerland). To quantify any $\mathrm{HOCl}$ deposition in more detail, the taurine-chloramine assay was performed as described before [7]. Briefly, a taurine buffer was diluted at 1:100 in gas plasma oxidized saline. Then, a developer solution containing sodium acetate, sodium iodide, and tetramethylbenzidine in dimethylformamide was added. Absorbance was measured at $645 \mathrm{~nm}$. Additionally, hydroxyl radicals $\left({ }^{\bullet} \mathrm{OH}\right)$ concentration was determined using the terephthalic acid assay [14]. The fluorescent hydroxylation product resulting from the reaction of terephthalic acid with hydroxyl radical was quantified by measuring an increase in fluorescence at $\lambda_{\mathrm{ex}} 318 \mathrm{~nm}$ and $\lambda_{\mathrm{em}} 426 \mathrm{~nm}$. Absolute concentrations of reactive species were calculated against a standard curve.

\subsection{Ehrlich Ascites Carcinoma (EAC) Mouse Model}

For the culture and treatment of Ehrlich Ascites Carcinoma (EAC) cells, male Swiss albino mice were used ( $25 \mathrm{~g}$ body weight). They were housed under standard laboratory conditions in clean plastic cages with an ad libitum supply of food and water. The experimental procedures were carried out under the guidelines of the ethics committee at the State University of Londrina/PR in Brazil (approval number: \#1633.2019.88). To minimize animal suffering, the $3 \mathrm{R}$ principles (reduce, refine, replace) were applied. For the induction of EAC, $5 \times 10^{7}$ cells were injected in $50 \mu \mathrm{L}$ phosphate-buffered saline (PBS) into the mice's peritoneal cavities. To investigate the ex vivo effect of POS on EAC cells, ascites fluid was extracted ten days post tumor inoculation. The evaluation of the in vivo efficacy of POS was done by repeated intraperitoneal injections of $1 \mathrm{~mL}$ of freshly prepared POS at days 2 , $4,6,8$, and 10 before they were euthanized on the following day. Several control groups were included. In addition to a group receiving untreated saline, one group received a concentration-matched (i.e., at the concentration found in POS) control of $\mathrm{H}_{2} \mathrm{O}_{2}$ experimentally spiked into the saline. In another control group, oxaliplatin (OXA; $0.5 \mathrm{mg} / \mathrm{kg}$ of body weight; Sigma-Aldrich, Taufkirchen, Germany) was added to saline and injected at days 5, 7, and 9. Finally, a fifth group received a combination of both OXA (at days 5, 7, and 9) and POS (at days 2, 4, 6, 8, and 10). At sacrifice, the animals were weighted, and the peritoneal ascitic fluid was collected, centrifuged at $1300 \times \mathrm{g}$ for $10 \mathrm{~min}$, supernatants were separated, and cells were washed three times with PBS. All samples were stored at $-20{ }^{\circ} \mathrm{C}$ for further downstream processing.

\subsection{Metabolic Activity}

After explantation from mice, EAC cells were washed three times with PBS, $1 \times 10^{6}$ EAC cells were grown into culture flasks in Dulbecco's minimal essential medium (DMEM; Thermo Fisher Scientific, Bremen, Germany), supplemented with $1 \%$ penicillin/streptomycin, $1 \%$ glutamine, and 10\% fetal bovine serum (all Sigma-Aldrich, Taufkirchen, Germany). For ex vivo treatment, $2 \times 10^{5}$ EAC cells were seeded into a 24-well plate, performed by incubation with a 1:1 mix of DMEM and POS (or fresh saline for control groups) for $48 \mathrm{~h}$. The number of adherent cells was quantified after administration of $0.5 \%$ trypan blue (Carl Roth, Karlsruhe, Germany) utilizing a Neubauer chamber. For the quantification of the percentage of metabolically active cells, the MTT (3-(4,5-dimethylthiazol-2yl)-2,5-diphenyltetrazolium bromide) assay (Sigma-Aldrich, Taufkirchen, Germany) was used. The assay indicates the ability of metabolically active cells to reduce the tetrazolium salt MTT to formazan that has a purple color and can be quantified using light absorbance. In control conditions, the antioxidant molecules or enzymes catalase $(1000 \mathrm{U} / \mathrm{mL}$; Sigma-Aldrich, St. Louis, MO, USA,), mannitol (25 mM; Nuclear, Diadema/SP,), and cPTIO (2-4-carboxyphenyl-4,4,5,5-tetramethylimidazoline-1-oxyl-3-oxide; $20 \mu \mathrm{M}$; Santa Cruz Biotecnologia, Dallas, TX, USA) were added 1:1 mix of DMEM and POS into the cells. 


\subsection{Systemic Oxidative Profile}

The liquid ascitic samples obtained from mice were separated into supernatant and the cellular fraction, mainly consisting of tumor cells. Subsequently, lipid peroxidation $(\mathrm{LOOH})$ analysis and total antioxidant capacity (TRAP) were evaluated in supernatants as previously described $[15,16]$. Lipid peroxidation results were reported in relative units of light per milligram of total protein (RUL/mg total protein), while TRAP results were expressed in $\mu \mathrm{M}$ of Trolox equivalents per milligram of total protein. In addition, catalase and superoxide dismutase (SOD) activities were evaluated in cellular fractions as previously described [17]. Briefly, cells were thawed and lysed with an Ultraturrax for $40 \mathrm{~s}$ on ice then centrifuged at $10,000 \times g$ for $10 \mathrm{~min}$ at $4{ }^{\circ} \mathrm{C}$. Next, supernatants were used for experiments. Results of catalase were expressed in velocity of absorbance decrease in $1 \mathrm{~min}$ per milligram of total protein $\left(\mathrm{V}_{\mathrm{abs}} / \mathrm{min} / \mathrm{mg}\right.$ total protein). At the same time, the amount of SOD capable of inhibiting in 50\% pyrogallol autoxidation was defined as a unit of enzymatic activity per milligram of total protein ( $\mathrm{U} / \mathrm{mg}$ total protein). An aliquot of all samples was used to determine total protein content by the Lowry technique, modified by Miller, using bovine serum albumin as standard as previously described $[18,19]$.

\subsection{Quantitative Immuno-Fluorescence Imaging}

Lavage-derived cells were isolated and washed with phosphate-buffered saline. Afterward, $1 \times 10^{6}$ cells were fixed with ice-cold methanol for $15 \mathrm{~min}$ at $-20{ }^{\circ} \mathrm{C}$ on microscopy glass slides. Blocking was performed using a blocking buffer containing PBS with 5\% FCS and 0.3\% Triton X-100 (Sigma-Aldrich, Taufkirchen, Germany) for $60 \mathrm{~min}$. For immunofluorescence imaging, the slides were incubated with antibodies targeted at cleaved caspase 3, antibodies targeting CD45 (rabbit anti-mouse; Cell Signaling Technologies, Frankfurt/M, Germany) in antibody staining buffer containing PBS with 1\% bovine serum albumin (Sigma-Aldrich, Taufkirchen, Germany), and 0.3\% Triton X-100 for $16 \mathrm{~h}$ at $4{ }^{\circ} \mathrm{C}$. Subsequently, the samples were incubated with fluorescently labeled (Alexa Fluor 488) secondary antibodies (goat anti-rabbit; Thermo Fisher Scientific, Bremen, Germany) and incubated for $1 \mathrm{~h}$ at room temperature. After several washing steps, the samples were mounted with antifade mounting medium with DAPI $\left(4^{\prime}, 6\right.$-diamidino-2phenylindole at $1 \mu \mathrm{M}$; Vector Laboratories, Burlingame, California USA). Images were acquired utilizing the Operetta CLS high-content imaging device (PerkinElmer, Hamburg, Germany), with a $20 \times$ air objective (NA $=0.4$; Zeiss, Jena, Germany) using the appropriate excitation wavelength and emission filter settings. Cell segmentation was performed utilizing algorithm-based tools of the Harmony imaging and analysis software (version 4.9; PerkinElmer, Hamburg, Germany) that separated the cells according to morphological properties. It quantified the mean fluorescence intensity of the cleaved-caspase or CD45 signal inside regions added via algorithms around the nuclear signals.

\subsection{Multiplex Cytokine Analysis}

Multiplex cytokine analysis was performed using a bead-based assay (BioLegend, Koblenz, Germany) according to the vendor's instructions. Briefly, lavage supernatants were incubated with antibody-coated beads, and mean fluorescence intensities (MFI) of each bead population (representing a single analyte) were determined using flow cytometry (CytoFLEX S; Beckman-Coulter, Krefeld, Germany). Total cytokine concentrations in picogram per milliliter were calculated against a known standard and using 5-log fitting with dedicated LEGENpPlex analysis software (version 8; BioLegend, Amsterdam, The Netherlands). To optimize compact data display in a single heatmap, data were normalized against the lavage of mice receiving untreated saline as control.

\subsection{Statistical Analysis}

Several technical and biological replicates were always carried out. Graphing and statistical analysis were performed utilizing Prism software (version 9.2; GraphPad Software, San Diego, CA, USA). To detect differences between two groups (e.g., control vs. POS), 
two-tailed $t$-tests were used. Multiple comparisons were carried out using $t$-test or one-way or two-way analysis of variances (ANOVA). The levels of significance are indicated as $\left.\left.p<0.05{ }^{*}\right), p<0.01{ }^{* *}\right)$, and $\left.p<0.001{ }^{* * *}\right)$.

\section{Results}

\subsection{Chemical Composition of POS and Its Effects on the Metabolic Activity of EAC Cells Ex Vivo}

In this work, we investigated the antitumor efficacy of plasma-oxidized saline (POS) in an Ehrlich Ascites Carcinoma (EAC) model (Figure 1a). To generate POS, the atmospheric pressure argon plasma jet kINPen MED was used (Figure 1b). The jet is known to generate large amounts of hydroxyl radicals and nitrogen radicals in the plasma gas phase, which react in liquids to a few long-lived species, for instance, hydrogen peroxide $\left(\mathrm{H}_{2} \mathrm{O}_{2}\right)$ and nitrite $\left(\mathrm{NO}_{2}{ }^{-}\right)$, respectively. Accordingly, the chemical composition of POS was analyzed. Upon plasma treatment, we observed a decline in $\mathrm{pH}$ (Figure 1c), which nevertheless was within the physiological range of medically approved saline solutions. $\mathrm{H}_{2} \mathrm{O}_{2}$ production is typical in POS, and deposition of $\mathrm{H}_{2} \mathrm{O}_{2}$ yielded a final concentration of $90 \mu \mathrm{M}$ in POS (Figure 1d). Furthermore, reactive nitrogen species such as nitrite $\left(\mathrm{NO}_{2}{ }^{-}\right)$and nitrate $\left(\mathrm{NO}_{3}{ }^{-}\right)$were produced (Figure 1e). The two redox-sensitive probes APF (Figure 1f) and HPF (Figure 1g) were added to POS after plasma treatment to identify other species generated in PBS. Both probes are oxidized by peroxynitrite ( $\left.{ }^{-} \mathrm{ONOO}\right)$ and hydroxyl radical $\left({ }^{\bullet} \mathrm{OH}\right)$, but only $\mathrm{APF}$ is sensitive to hypochlorous acid. When comparing the species-dependent oxidation of both probes to direct treatment conditions, only marginal fluorescence was observed in POS, indicating a negligible production of the respective species. This was confirmed by direct quantification of hypochlorous acid (Figure $1 \mathrm{~h}$ ) and hydroxyl radical (Figure 1i) in POS.

To test the anticancer efficacy of POS, EAC cells were grown in Swiss albino mice before they were explanted from the ascites fluid, and $2 \times 10^{5}$ cells were exposed to a mix of cell culture medium and plasma-oxidized saline (Figure 1a). The total number of adherent EAC cells was significantly greater in the groups that had received untreated saline compared to the group receiving POS when analyzed after $24 \mathrm{~h}$ or $48 \mathrm{~h}$ of incubation (Figure 1k). The number of non-adherent cells was not significantly changed in the treatment. However, an overall trend towards greater number of non-adherent cells was observed in POS conditions, suggesting apoptosis of adherent cells floating in the supernatant as non-adherent cells. Previous reports also suggested plasma treatment leading to detachment of adherent cells. To investigate whether the phenome was related to cell death or detachment, these cells were analyzed for their viability using the Trypan Blue exclusion assay. Expressed as percentages after $48 \mathrm{~h}$ of incubation, viability of $70 \%$ to $93 \%$ in control cells compared to only $2 \%$ in the POS-treated cells was found. These data indicated substantial toxicity of POS when applied in vitro to the cells harvested for ex vivo experiments. Moreover, the metabolic activity was analyzed and also significantly decreased after exposure to POS. This effect was modest but significant even at $1 \mathrm{~h}$ of incubation with POS already and increased to its most assertive extent $48 \mathrm{~h}$ later (Figure 11). To confirm that reactive oxygen species (ROS) were the critical mediators of cytotoxicity, the metabolic activity was analyzed in samples having received the antioxidant enzyme catalase or the antioxidants mannitol and cPTIO. The enzyme fully abrogated cytotoxic effects, while the antioxidants partially reduced the POS-mediated toxicity in EAC cells (Figure 1m). This indicated a prominent role of the plasma-derived ROS in general and of $\mathrm{H}_{2} \mathrm{O}_{2}$ particularly inside the saline and suggested POS to have potent antitumor toxicity. 


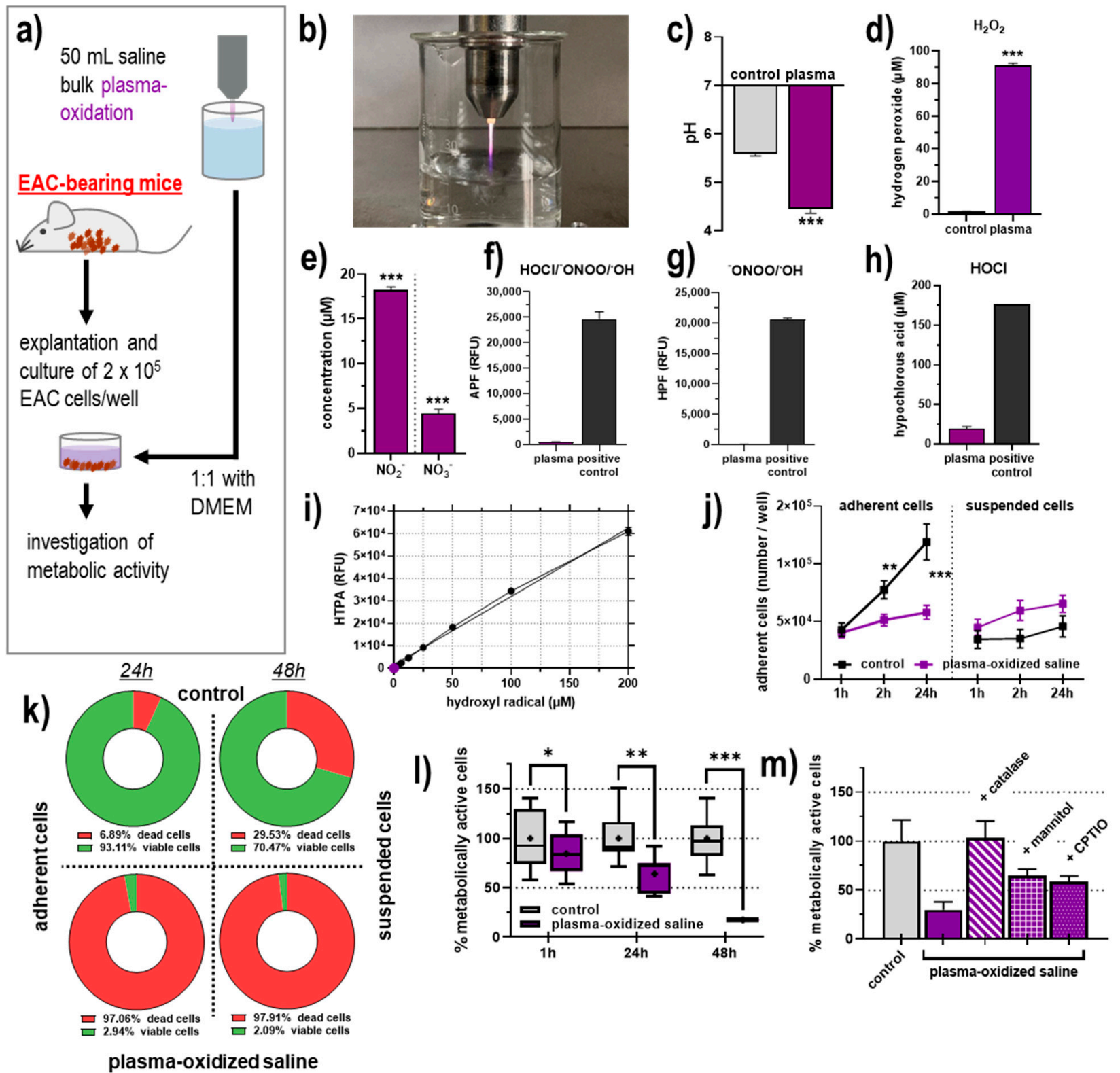

Figure 1. Plasma-oxidized saline reduced the metabolic activity of EAC cells ex vivo. (a) Schematic overview of experimental procedures; (b) representative image of kINPen plasma oxidation of $20 \mathrm{~mL}$ saline; (c) pH in plasma-oxidized saline; quantification of $(\mathbf{d})$ hydrogen peroxide $\left(\mathrm{H}_{2} \mathrm{O}_{2}\right),(\mathbf{e})$ nitrite $\left(\mathrm{NO}_{2}{ }^{-}\right)$, and nitrate $\left(\mathrm{NO}_{3}{ }^{-}\right)$in plasma-oxidized saline; relative fluorescence intensity (RFU) of oxidized (f) APF and (g) HPF due to respective species in plasma-oxidized saline, direct treatment of the redox sensitive probes served as positive control for production of reactive species; quantification of (h) hypochlorous acid $(\mathrm{HOCl})$ and $(\mathbf{i})$ hydroxyl radical $\left({ }^{\bullet} \mathrm{OH}\right)$ in liquids, plasma treatment with $\mathrm{HeO}_{2}$ as feed gas was used as a positive control for $\mathrm{HOCl}$ production; (j) number of viable adherent EAC cells after explantation and incubation with either plasma-oxidized saline or untreated saline for $48 \mathrm{~h}$; (k) percentage of adherent cells after $24 \mathrm{~h}$ and $48 \mathrm{~h}$ of POS treatment; (1) metabolic activity of EAC cells $1 \mathrm{~h}, 24 \mathrm{~h}$, and $48 \mathrm{~h}$ post-incubation of plasma-oxidized or untreated saline; (m) metabolic activity of EAC cells $48 \mathrm{~h}$ after incubation with untreated or plasma-oxidized saline with the antioxidants catalase, mannitol, and cPTIO. Data are mean \pm SEM of at least three independent experiments, statistical analysis was performed using t-test or one-way ANOVA with $p<0.05\left(^{*}\right), p<0.01\left({ }^{* *}\right)$, and $p<0.001\left(^{* * *}\right)$. EAC = Ehrlich Ascites Carcinoma; $\mathrm{HTPA}=$ hydroxyterephthalate; APF = fluorescence response of $3^{\prime}(\mathrm{p}$-aminophenyl) fluorescein; $\mathrm{HPF}=(\mathrm{p}$-hydroxyphenyl $)$ fluorescein. 


\subsection{POS Reduced EAC Burden and Altered Antioxidant Capacity In Vivo}

To test the efficacy of POS in vivo, EAC-bearing mice received repeated injections into the peritoneal cavity (Figure 2a). The saline was left untreated, and mice were exposed to cold physical plasma, received oxaliplatin (OXA, $0.5 \mathrm{mg} / \mathrm{kg}$ body weight) alone or in combination with POS, or received a POS-concentration-matched spike-in of $\mathrm{H}_{2} \mathrm{O}_{2}$, resulting in a total of five treatment groups. One day after the fifth and last injection, ascites fluid was collected. The analysis of the total amounts of cells in the ascites revealed a significant reduction in the POS, OXA, and plasma-OXA but not the $\mathrm{H}_{2} \mathrm{O}_{2}$ group (Figure 2b). Subsequent elaboration of the percentage of viable cells showed a significant increase of dead cells in the treatment regimens of POS, OXA, and plasma-OXA applied in vivo (Figure 2c). New therapeutic approaches not only need to be effective but also safe. Accordingly, the weight and food intake of animals was monitored. While the OXA treatment showed the best antitumor capacity (Figure 2a,b), the animals also showed weight loss and less food intake, suggesting the drug to be toxic to a certain extent (Figure 2d). By contrast, the POS treatment did not induce such changes. To further explore the treatments' effects, the cells and the supernatant were obtained from the tumor ascites. In the supernatant, the total radical-trapping antioxidant parameter (TRAP) and lipid peroxidation was analyzed. The POS and OXA treatment did not significantly alter, while it was surprising to find plasma-OXA and $\mathrm{H}_{2} \mathrm{O}_{2}$ to reduce the TRAP (Figure 2e) significantly. This suggests that this combination can alter the redox balance of this environment, which is often accompanied by lipid peroxidation. To analyze this possibility, the extent of lipid peroxidation was further profiled in the ascites supernatants. The plasma, OXA, and plasma-OXA groups but not $\mathrm{H}_{2} \mathrm{O}_{2}$ treatment were associated with significantly enhanced lipid peroxidation (Figure $2 \mathrm{f}$ ). To understand the apparent discrepancy between reduced TRAP but unchanged lipid peroxidation levels, the enzymatic activity of two antioxidative enzymes, catalase removing $\mathrm{H}_{2} \mathrm{O}_{2}$, and superoxide dismutase (SOD) dismutating superoxide, was analyzed in the ascites cells. The $\mathrm{H}_{2} \mathrm{O}_{2}$ group showed significantly enhanced catalase activity, while all other groups did not (Figure $2 \mathrm{~g}$ ), suggesting that $\mathrm{H}_{2} \mathrm{O}_{2}$ spurs $\mathrm{H}_{2} \mathrm{O}_{2}$-focused and catalasebased antioxidant defense in the peritoneal cavity, which might affect global resources to counteract ROS, possibly resulting in decreased TRAP levels. For SOD, none of the groups showed a significant increase in its activity (Figure 2g).

\subsection{POS Elicited Apoptosis and Modest Inflammatory Changes in the Tumor Microenvironment of the Peritoneal Cavity}

To investigate the tumor-toxic mode of action in vivo, the EAC cells were collected after the experiment, fixed onto microscopy slides (Figure 3a), stained for active caspase 3 , and analyzed using quantitative imaging (Figure 3b). The POS but not the $\mathrm{H}_{2} \mathrm{O}_{2}$ treatment resulted in significantly enhanced signal intensities (Figure 3c). The analysis of tumor-infiltrating leukocytes is of great current interest when investigating the tumor microenvironment (TME). To this end, we stained the samples with anti-CD45 antibodies capable of identifying leukocytes. However, no significant differences were observed in both POS and $\mathrm{H}_{2} \mathrm{O}_{2}$ treatment (Figure 3d). Nevertheless, immuno-relevant changes can also occur for soluble inflammatory mediators, such as cytokines. To this end, we quantified several cytokines in the lavage supernatants of tumor-bearing mice using multiplex beadbased flow cytometry. A modest but significant increase of interleukin (IL)-6, IL-9, IL-10, IL17A, IL-22, and interferon (IFN) $\gamma$ was observed for POS treatment in the EAC model (Figure 3e). Except for the lack of IL-10, OXA treatment gave a similar but much more pronounced response, with additional increases observed for IL-4, IL-5, and tumor necrosis factor (TNF) $\alpha$ when compared against the control. Thus, the combination of POS with OVA seemingly attenuated the levels of the significantly elevated cytokines in the OXA group for each group compared controls. For $\mathrm{H}_{2} \mathrm{O}_{2}$, none of the targets investigated showed a significantly changed increase or decrease compared to the control group, indicating its minor role in the local inflammatory pattern of the peritoneal TME. 

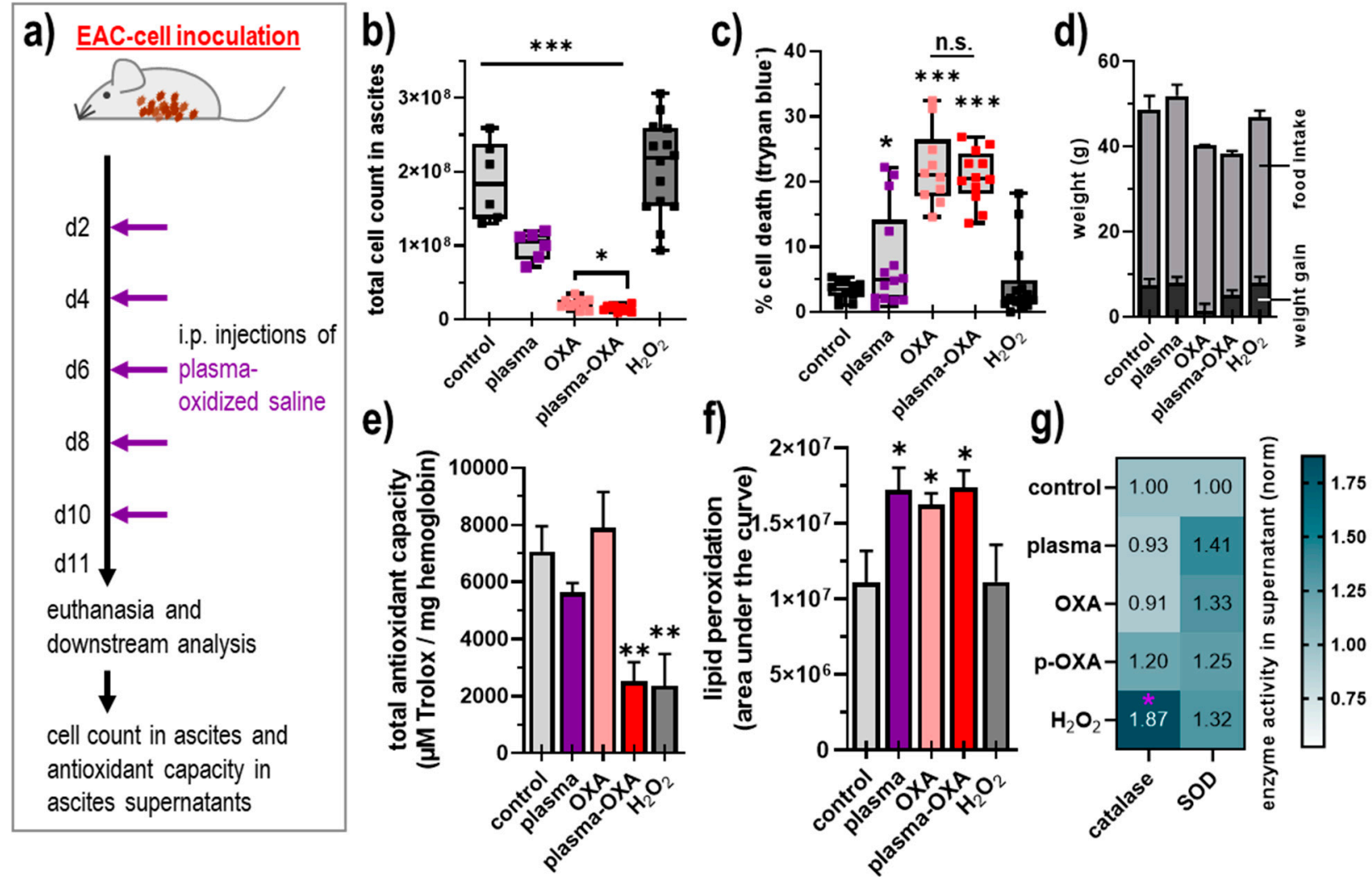

Figure 2. Plasma-oxidized saline reduced EAC burden and antioxidant capacity in vivo. (a) Schematic overview of experimental procedures; (b) total cell count in lavage fluids explanted from EAC-bearing mice that received injections of plasma-oxidized or untreated saline; (c) percentage of dead cells in the lavage; (d) cumulative body weight gain and total food intake of mice at day 11; (e) total antioxidant capacity in ascites supernatants from EAC-bearing mice that had received injections of plasma-oxidized or untreated saline; (f) lipid peroxidation (absolute luminescence units) in erythrocytes of the animals tested; (g) enzyme activity of catalase and SOD in ascites supernatants of the animals tested. Data are mean \pm SEM of at least three mice per group, statistical analysis was performed using $t$-test or one-way or two-way ANOVA with $p<0.05\left(^{*}\right), p<0.01\left(^{* *}\right)$, and $p<0.001\left(^{* * *}\right)$ and the purple star $(\mathrm{g})$ denoting $p<0.05\left(^{*}\right)$ compared against control. $\mathrm{EAC}=$ Ehrlich Ascites Carcinoma, OXA = oxaliplatin, i.p. = intraperitoneal, p(lasma)-OXA = plasma + oxaliplatin, $\mathrm{SOD}=$ superoxide dismutase. 

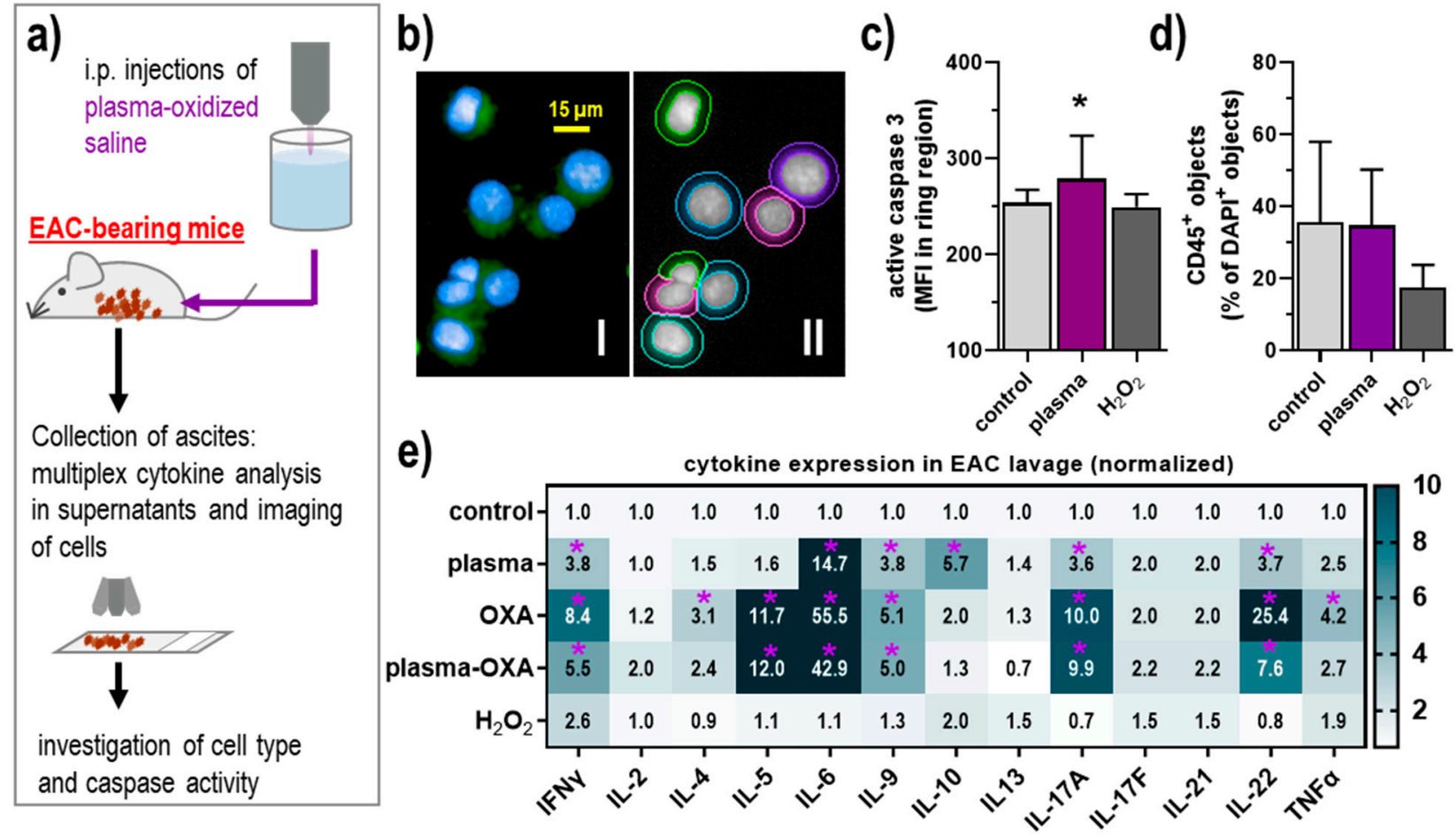

Figure 3. Plasma-oxidized saline showed no acute toxicity in the lavage of EAC-bearing mice while significantly altering the inflammatory profile in the peritoneal cavity. (a) Schematic overview of experimental procedures; (b) representative images of cells from lavage liquids of EAC-bearing mice with nuclear counterstaining (DAPI, blue) and active caspase 3 stainings (green), and software-based segmentation of cells; (c,d) quantification of the staining of active caspase 3 (c) and CD45 (d) in cells explanted from EAC-bearing mice that received injections of plasma-oxidized or untreated saline; (e) 13-plex cytokine quantification of supernatants of lavages with data normalized to controls. Data are mean + SEM of at least three mice per group, statistical analysis was performed using one-way ANOVA with $p<0.05\left(^{*}\right)$, or two-way ANOVA with $p<0.05(*$, purple) for more than three-fold changes. EAC $=$ Ehrlich Ascites Carcinoma, OXA = oxaliplatin, i.p. $=$ intraperitoneal, $\mathrm{p}$ (lasma)-OXA = plasma + oxaliplatin, $\mathrm{IL}=$ interleukin, IFN $=$ interferon, $\mathrm{TNF}=$ tumor necrosis factor.

\section{Discussion}

Peritoneal metastasis (PC) requires novel treatment avenues to combat cancer dissemination. Treatment with reactive oxygen species (ROS) might be a promising way of mediating anticancer effects locally and with few side effects [4]. Generating ROS-enriched liquids, e.g., via cold physical plasma treatment of medically accredited saline, is an innovative new option for such an application. Hence, we explored the anticancer efficacy and tolerability of plasma-oxidized saline (POS) in an intraperitoneal tumor model system, the Ehrlich Ascites Carcinoma (EAC).

The idea of using cold physical plasma-oxidized liquid as an anticancer tool emerged some years ago already [20]. Most studies focused on using plasma-oxidized cell culture media, the so-called plasma-activated medium (PAM). Traditionally, PAM is the directly plasma-oxidized cell culture medium, while some reports also regard in-medium-diluted POS, such as used in the experiments in Figure 1 of this study, as PAM. Several studies demonstrated that PAM could selectively eradicate cancer cells grown in 2D cultures [21] and 3D multicellular spheroids [22]. These and other studies also outlined the chemical composition of PAM, and the ROS/RNS deposited in these media might act synergistically to promote tumor cell death [23-25]. Mechanistically, PAM was found to affect p53 signaling [26], cause zinc liberation [27], and affect mitochondria [28]. We and others also found PAM to have additive or synergistic drugs such as complex I inhibitors [29], histone acetylase inhibitors [30], and the chemotherapeutic gemcitabine [31] that are used in the treatment of pancreatic PC of patients in the clinics [32]. In support of this, PAM reduced 
pancreatic tumor peritoneal metastasis in vivo [33]. Many studies using plasma-oxidized liquids implicate apoptosis as the primary mode of cell death in cancer cells [34], as also suggested in this work based on caspase 3 cleavage. Whether the extrinsic or intrinsic apoptotic pathway was activated due to in vivo application of POS in our results remains to be elucidated in future studies.

However, the limitation of PAM is that it is not accredited as a medical product because of the complex structure of cell culture medium and several hard-to-standardize components. By contrast, several other liquids such as Ringer's lactate and $\mathrm{NaCl}$ are frequently used liquids in clinics [35], and both were found to be suitable for anticancer action and stability in our previous pilot study using the accredited argon plasma jet kINPen [9], making our current approach in principle eligible for case studies in patients. Previous studies found that plasma-treated Ringer's lactate was effective against pancreatic cancer in vitro and in vivo [35], and it was reported to have a more vigorous activity than PAM [36]. Plasma-treated Ringer's lactate was also found to be effective against other cancer entities such as ovarian cancer [37] and glioblastoma [38,39], in which a link to oxidative stress responses and altered tumor metabolism was suggested. As a redox mechanism of action, the ROS chemistry in plasma-treated Ringer's lactate involves the generation of $\mathrm{H}_{2} \mathrm{O}_{2}$, which, however, depends on the concentration of lactate in a nonlinear fashion [40]. Moreover, the lactate itself was suggested as an active component in these liquids [41]. Although lacking lactate, plasma-oxidized phosphate-buffered saline (PBS) was found to have high antitumor toxicity as well [42], also in 3D tumor spheroids of glioblastoma [43]. Interestingly, plasma-oxidized PBS also elicited immunogenic cancer cell death (ICD) in colorectal cancer [10] as well as in pancreatic cancer cells [44]. ICD is known to promote antitumor immunity and is a promising mode of action in both oncology and the field of plasma biomedical sciences [45]. Studies on plasma-oxidized saline in anticancer treatment, however, are scarce so far.

Similar to our findings, $\mathrm{CPTIO}$ - a nitric oxide scavenger-was previously found to reduce the cytotoxic effects of plasma-treated PBS on cancer cells [46]. This suggests a role of reactive nitrogen species (RNS) in addition to ROS. RNS such as nitric oxide were proposed to co-evolve from chemical reactions of POS with several enzymes at the tumor cell membrane [47]. It was interesting to note a minor but measurable amount of $\mathrm{HOCl}$ in the POS, which stems from cold physical plasma-derived atomic and singlet delta oxygen [48]. At $\mathrm{pH} 7, \mathrm{H}_{2} \mathrm{O}_{2}$ and $\mathrm{HOCl}$ scavenge each other, but at $\mathrm{pH} 4.6$, both species seem to co-exist to some extent, at least immediately following the physical plasma treatment of the saline solution. $\mathrm{H}_{2} \mathrm{O}_{2}$ is a known agent in POS chemistry, as it can trigger Fenton chemistry and ferroptosis at and in cells [49]. However, $\mathrm{H}_{2} \mathrm{O}_{2}$ treatment alone did not replicate the action of POS, suggesting additional effectors to be at play. Both $\mathrm{H}_{2} \mathrm{O}_{2}$ and POS were well-tolerated by the animals in contrast to doxorubicin. The drug is known for its side effects [50] and its anticancer efficacy. Our data on the combination of POS and oxaliplatin suggest a very modest but nevertheless significant reduction in tumor cells, which is in line with previous in vitro reports [51-53]. Interestingly, the combination treatment attenuated the oxaliplatin-induced inflammation in the peritoneal cavity, as observed by a decrease of, e.g., the cytokines IL- 6 and IL-22 that are known to promote immuno-infiltration and activation of professional antigen-presenting cells, and to exacerbate inflammatory T-cell responses $[54,55]$. This suggests that POS decrease potentially toxic inflammatory side effects of oxaliplatin elicited not only in the tumor cells but also the non-malignant bystander cells in the peritoneal cavity. A reason for this might be the increased IL-10 levels seen in the POS condition, a factor observed to be released by, for instance, regulatory $\mathrm{T}$ cells that may have contributed to dampened inflammation [56] in the POS-OXA combination setting. The POS, OXA, and plasma-OXA conditions were also accompanied by increased levels of IFN $\gamma$, a cytokine known for its potent antitumor effects and enhancement of the antigen-presenting machinery facilitating elevated antitumor immunity [57,58]. Along similar lines, increased IL-9 levels were observed in those three conditions, pointing to a potential involvement of $\mathrm{T}_{\mathrm{H}} 9$ cells reported to exert antitumor 
activity [59]. Similarly, IL-17 is a hallmark of antitumor $\mathrm{T}_{\mathrm{H}} 17$ cells with profound anticancer capacity [60] and elevated IL-17 concentrations were observed in POS and OXA treatments.

In summary, it was found that POS did not cause side effects known by other chemotherapeutic agents used to treat cancer. Moreover, POS potentiated the action of OXA, decreased the antioxidant capacity of ascitic fluid, and increased lipid peroxidation that might aid in making tumor cells more susceptible to death.

\section{Conclusions}

This study suggests that our approach of combining plasma-oxidized saline with chemotherapy for targeting peritoneal carcinomatosis is promising, and further research is warranted to employ such combination therapy in a disease-specific context.

Author Contributions: Conceptualization, A.L.C. and S.B.; methodology, E.F., A.L.C., G.P.-M., L.M., L.J.S. and S.B.; software, E.F.; validation, W.A.S.B., E.F., G.P.-M. and T.D.H.d.N.; formal analysis, W.A.S.B., L.J.S., E.F., L.M., T.D.H.d.N., W.C.F., J.H.R.D. and S.B.; investigation, W.A.S.B., E.F., G.P.-M., L.J.S., T.D.H.d.N., W.C.F., J.H.R.D. and L.M.; resources, A.L.C. and S.B.; data curation, W.A.S.B., E.F., L.M. and S.B.; writing —original draft preparation, S.B.; writing—review and editing, W.A.S.B., E.F., A.L.C. and S.B.; visualization, E.F., L.M. and S.B.; supervision, A.L.C. and S.B.; project administration, A.L.C. and S.B.; funding acquisition, A.L.C. and S.B. All authors have read and agreed to the published version of the manuscript.

Funding: Funding was received by the German Federal Ministry of Education and Research (grant numbers 03Z22DN11, 03Z22Di1, and 03Z22D511).

Institutional Review Board Statement: The experimental procedures with mice were carried out under the guidelines of the ethics committee at the State University of Londrina/PR in Brazil (approval number: \#1633.2019.88).

Informed Consent Statement: Not applicable.

Data Availability Statement: The data of this study are available from the corresponding authors upon reasonable request.

Acknowledgments: The authors acknowledge the technical support of Jesus A. Vargas and Rajesh Kumar Gandhirajan in pilot experiments and fruitful discussions.

Conflicts of Interest: The authors have no conflict of interest to declare.

\section{References}

1. Jacquet, P.; Sugarbaker, P.H. Clinical research methodologies in diagnosis and staging of patients with peritoneal carcinomatosis. Cancer Treat. Res. 1996, 82, 359-374. [CrossRef]

2. Verwaal, V.J.; Bruin, S.; Boot, H.; van Slooten, G.; van Tinteren, H. 8-year follow-up of randomized trial: Cytoreduction and hyperthermic intraperitoneal chemotherapy versus systemic chemotherapy in patients with peritoneal carcinomatosis of colorectal cancer. Ann. Surg. Oncol. 2008, 15, 2426-2432. [CrossRef] [PubMed]

3. Gill, R.S.; Al-Adra, D.P.; Nagendran, J.; Campbell, S.; Shi, X.; Haase, E.; Schiller, D. Treatment of gastric cancer with peritoneal carcinomatosis by cytoreductive surgery and hipec: A systematic review of survival, mortality, and morbidity. J. Surg. Oncol. 2011, 104, 692-698. [CrossRef] [PubMed]

4. Trachootham, D.; Alexandre, J.; Huang, P. Targeting cancer cells by ros-mediated mechanisms: A radical therapeutic approach? Nat. Rev. Drug Discov. 2009, 8, 579-591. [CrossRef]

5. Reuter, S.; von Woedtke, T.; Weltmann, K.D. The kinpen-a review on physics and chemistry of the atmospheric pressure plasma jet and its applications. J. Phys. D Appl. Phys. 2018, 51, 233001. [CrossRef]

6. Bekeschus, S.; Schmidt, A.; Niessner, F.; Gerling, T.; Weltmann, K.D.; Wende, K. Basic research in plasma medicine-A throughput approach from liquids to cells. J. Vis. Exp. 2017, e56331. [CrossRef]

7. Bekeschus, S.; Clemen, R.; Niessner, F.; Sagwal, S.K.; Freund, E.; Schmidt, A. Medical gas plasma jet technology targets murine melanoma in an immunogenic fashion. Adv. Sci. 2020, 7, 1903438. [CrossRef]

8. Bekeschus, S.; Moritz, J.; Helfrich, I.; Boeckmann, L.; Weltmann, K.D.; Emmert, S.; Metelmann, H.R.; Stoffels, I.; von Woedtke, T. Ex vivo exposure of human melanoma tissue to cold physical plasma elicits apoptosis and modulates inflammation. Appl. Sci. 2020, 10, 1971. [CrossRef]

9. Freund, E.; Liedtke, K.R.; Gebbe, R.; Heidecke, A.K.; Partecke, L.-I.; Bekeschus, S. In vitro anticancer efficacy of six different clinically approved types of liquids exposed to physical plasma. IEEE Trans. Rad. Plasma Med. Sci. 2019, 3, 588-596. [CrossRef] 
10. Freund, E.; Liedtke, K.R.; van der Linde, J.; Metelmann, H.R.; Heidecke, C.D.; Partecke, L.I.; Bekeschus, S. Physical plasma-treated saline promotes an immunogenic phenotype in ct26 colon cancer cells in vitro and in vivo. Sci. Rep. 2019, 9, 634. [CrossRef]

11. Bekeschus, S.; Schmidt, A.; Weltmann, K.-D.; von Woedtke, T. The plasma jet kinpen-A powerful tool for wound healing. Clin. Plasma Med. 2016, 4, 19-28. [CrossRef]

12. Bekeschus, S.; Lin, A.; Fridman, A.; Wende, K.; Weltmann, K.D.; Miller, V. A comparison of floating-electrode dbd and kinpen jet: Plasma parameters to achieve similar growth reduction in colon cancer cells under standardized conditions. Plasma Chem. Plasma Process. 2018, 38, 1-12. [CrossRef]

13. Setsukinai, K.; Urano, Y.; Kakinuma, K.; Majima, H.J.; Nagano, T. Development of novel fluorescence probes that can reliably detect reactive oxygen species and distinguish specific species. J. Biol. Chem. 2003, 278, 3170-3175. [CrossRef]

14. Charbouillot, T.; Brigante, M.; Mailhot, G.; Maddigapu, P.R.; Minero, C.; Vione, D. Performance and selectivity of the terephthalic acid probe for oh as a function of temperature, ph and composition of atmospherically relevant aqueous media. J. Photochem. Photobiol. A Chem. 2011, 222, 70-76. [CrossRef]

15. Flecha, B.G.; Llesuy, S.; Boveris, A. Hydroperoxide-initiated chemiluminescence-An assay for oxidative stress in biopsies of heart, liver, and muscle. Free Radic. Biol. Med. 1991, 10, 93-100. [CrossRef]

16. Repetto, M.; Reides, C.; Gomez Carretero, M.L.; Costa, M.; Griemberg, G.; Llesuy, S. Oxidative stress in blood of hiv infected patients. Clin. Chim. Acta 1996, 255, 107-117. [CrossRef]

17. Marklund, S.; Marklund, G. Involvement of the superoxide anion radical in the autoxidation of pyrogallol and a convenient assay for superoxide dismutase. Eur. J. Biochem. 1974, 47, 469-474. [CrossRef]

18. Lowry, O.H.; Rosebrough, N.J.; Farr, A.L.; Randall, R.J. Protein measurement with the folin phenol reagent. J. Biol. Chem. 1951, 193, 265-275. [CrossRef]

19. Miller, G.L. Protein determination for large numbers of samples. Anal. Chem. 1959, 31, 964. [CrossRef]

20. Tanaka, H.; Mizuno, M.; Ishikawa, K.; Takeda, K.; Nakamura, K.; Utsumi, F.; Kajiyama, H.; Kano, H.; Okazaki, Y.; Toyokuni, S.; et al. Plasma medical science for cancer therapy: Toward cancer therapy using nonthermal atmospheric pressure plasma. IEEE Trans. Plasma Sci. 2014, 42, 3760-3764. [CrossRef]

21. Torii, K.; Yamada, S.; Nakamura, K.; Tanaka, H.; Kajiyama, H.; Tanahashi, K.; Iwata, N.; Kanda, M.; Kobayashi, D.; Tanaka, C.; et al. Effectiveness of plasma treatment on gastric cancer cells. Gastric Cancer 2015, 18, 635-643. [CrossRef]

22. Judee, F.; Fongia, C.; Ducommun, B.; Yousfi, M.; Lobjois, V.; Merbahi, N. Short and long time effects of low temperature plasma activated media on 3d multicellular tumor spheroids. Sci. Rep. 2016, 6, 21421. [CrossRef]

23. Bauer, G. Targeting protective catalase of tumor cells with cold atmospheric plasma- activated medium (pam). Anticancer Agents Med. Chem. 2018, 18, 784-804. [CrossRef] [PubMed]

24. Attri, P.; Park, J.H.; Ali, A.; Choi, E.H. How does plasma activated media treatment differ from direct cold plasma treatment? Anticancer Agents Med. Chem. 2018, 18, 805-814. [CrossRef]

25. Bauer, G.; Sersenova, D.; Graves, D.B.; Machala, Z. Cold atmospheric plasma and plasma-activated medium trigger rons-based tumor cell apoptosis. Sci. Rep. 2019, 9, 14210. [CrossRef] [PubMed]

26. Shi, L.; Yu, L.; Zou, F.; Hu, H.; Liu, K.; Lin, Z. Gene expression profiling and functional analysis reveals that p53 pathway-related gene expression is highly activated in cancer cells treated by cold atmospheric plasma-activated medium. PeerJ 2017, 5, e3751. [CrossRef]

27. Hara, H.; Kobayashi, M.; Shiiba, M.; Kamiya, T.; Adachi, T. Sublethal treatment with plasma-activated medium induces senescence-like growth arrest of a549 cells: Involvement of intracellular mobile zinc. J. Clin. Biochem. Nutr. 2019, 65, 16-22. [CrossRef] [PubMed]

28. Adachi, T.; Tanaka, H.; Nonomura, S.; Hara, H.; Kondo, S.; Hori, M. Plasma-activated medium induces a549 cell injury via a spiral apoptotic cascade involving the mitochondrial-nuclear network. Free Radic. Biol. Med. 2015, 79, 28-44. [CrossRef] [PubMed]

29. Gandhirajan, R.K.; Rodder, K.; Bodnar, Y.; Pasqual-Melo, G.; Emmert, S.; Griguer, C.E.; Weltmann, K.D.; Bekeschus, S. Cytochrome c oxidase inhibition and cold plasma-derived oxidants synergize in melanoma cell death induction. Sci. Rep. 2018, 8, 12734. [CrossRef]

30. Adachi, T.; Kano, A.; Nonomura, S.; Kamiya, T.; Hara, H. Histone deacetylase inhibitors stimulate the susceptibility of a549 cells to a plasma-activated medium treatment. Arch. Biochem. Biophys. 2016, 606, 120-127. [CrossRef]

31. Masur, K.; von Behr, M.; Bekeschus, S.; Weltmann, K.D.; Hackbarth, C.; Heidecke, C.D.; von Bernstorff, W.; von Woedtke, T.; Partecke, L.I. Synergistic inhibition of tumor cell proliferation by cold plasma and gemcitabine. Plasma Process. Polym. 2015, 12, 1377-1382. [CrossRef]

32. Tentes, A.A.; Kyziridis, D.; Kakolyris, S.; Pallas, N.; Zorbas, G.; Korakianitis, O.; Mavroudis, C.; Courcoutsakis, N.; Prasopoulos, P. Preliminary results of hyperthermic intraperitoneal intraoperative chemotherapy as an adjuvant in resectable pancreatic cancer. Gastroenterol. Res. Pract. 2012, 2012, 506571. [CrossRef]

33. Liedtke, K.R.; Bekeschus, S.; Kaeding, A.; Hackbarth, C.; Kuehn, J.P.; Heidecke, C.D.; von Bernstorff, W.; von Woedtke, T.; Partecke, L.I. Non-thermal plasma-treated solution demonstrates antitumor activity against pancreatic cancer cells in vitro and in vivo. Sci. Rep. 2017, 7, 8319. [CrossRef]

34. Duan, J.; Lu, X.; He, G. The selective effect of plasma activated medium in an in vitro co-culture of liver cancer and normal cells. J. Appl. Phys. 2017, 121, 013302. [CrossRef] 
35. Tanaka, H.; Bekeschus, S.; Yan, D.; Hori, M.; Keidar, M.; Laroussi, M. Plasma-treated solutions (pts) in cancer therapy. Cancers 2021, 13, 1737. [CrossRef] [PubMed]

36. Matsuzaki, T.; Kano, A.; Kamiya, T.; Hara, H.; Adachi, T. Enhanced ability of plasma-activated lactated ringer's solution to induce a549cell injury. Arch. Biochem. Biophys. 2018, 656, 19-30. [CrossRef]

37. Bisag, A.; Bucci, C.; Coluccelli, S.; Girolimetti, G.; Laurita, R.; De Iaco, P.; Perrone, A.M.; Gherardi, M.; Marchio, L.; Porcelli, A.M.; et al. Plasma-activated ringer's lactate solution displays a selective cytotoxic effect on ovarian cancer cells. Cancers 2020, 12, 476. [CrossRef]

38. Ishikawa, K.; Hosoi, Y.; Tanaka, H.; Jiang, L.; Toyokuni, S.; Nakamura, K.; Kajiyama, H.; Kikkawa, F.; Mizuno, M.; Hori, M. Non-thermal plasma-activated lactate solution kills u251sp glioblastoma cells in an innate reductive manner with altered metabolism. Arch. Biochem. Biophys. 2020, 688, 108414. [CrossRef]

39. Tanaka, H.; Mizuno, M.; Katsumata, Y.; Ishikawa, K.; Kondo, H.; Hashizume, H.; Okazaki, Y.; Toyokuni, S.; Nakamura, K.; Yoshikawa, N.; et al. Oxidative stress-dependent and -independent death of glioblastoma cells induced by non-thermal plasma-exposed solutions. Sci. Rep. 2019, 9, 13657. [CrossRef]

40. Liu, Y.; Ishikawa, K.; Miron, C.; Hashizume, H.; Tanaka, H.; Hori, M. Hydrogen peroxide in lactate solutions irradiated by non-equilibrium atmospheric pressure plasma. Plasma Sources Sci. Technol. 2020, 30, 4. [CrossRef]

41. Tanaka, H.; Nakamura, K.; Mizuno, M.; Ishikawa, K.; Takeda, K.; Kajiyama, H.; Utsumi, F.; Kikkawa, F.; Hori, M. Non-thermal atmospheric pressure plasma activates lactate in ringer's solution for anti-tumor effects. Sci. Rep. 2016, 6, 36282. [CrossRef]

42. Van Boxem, W.; Van der Paal, J.; Gorbanev, Y.; Vanuytsel, S.; Smits, E.; Dewilde, S.; Bogaerts, A. Anti-cancer capacity of plasma-treated pbs: Effect of chemical composition on cancer cell cytotoxicity. Sci. Rep. 2017, 7, 16478. [CrossRef]

43. Privat-Maldonado, A.; Gorbanev, Y.; Dewilde, S.; Smits, E.; Bogaerts, A. Reduction of human glioblastoma spheroids using cold atmospheric plasma: The combined effect of short- and long-lived reactive species. Cancers 2018, 10, 394. [CrossRef]

44. Van Loenhout, J.; Flieswasser, T.; Freire Boullosa, L.; De Waele, J.; Van Audenaerde, J.; Marcq, E.; Jacobs, J.; Lin, A.; Lion, E.; Dewitte, H.; et al. Cold atmospheric plasma-treated pbs eliminates immunosuppressive pancreatic stellate cells and induces immunogenic cell death of pancreatic cancer cells. Cancers 2019, 11, 1597. [CrossRef]

45. Bekeschus, S.; Clemen, R.; Metelmann, H.-R. Potentiating anti-tumor immunity with physical plasma. Clin. Plasma Med. 2018, 12, 17-22. [CrossRef]

46. Iuchi, K.; Morisada, Y.; Yoshino, Y.; Himuro, T.; Saito, Y.; Murakami, T.; Hisatomi, H. Cold atmospheric-pressure nitrogen plasma induces the production of reactive nitrogen species and cell death by increasing intracellular calcium in hek293t cells. Arch. Biochem. Biophys. 2018, 654, 136-145. [CrossRef] [PubMed]

47. Bauer, G. Intercellular singlet oxygen-mediated bystander signaling triggered by long-lived species of cold atmospheric plasma and plasma-activated medium. Redox Biol. 2019, 26, 101301. [CrossRef] [PubMed]

48. Bekeschus, S.; Wende, K.; Hefny, M.M.; Rodder, K.; Jablonowski, H.; Schmidt, A.; Woedtke, T.V.; Weltmann, K.D.; Benedikt, J. Oxygen atoms are critical in rendering thp-1 leukaemia cells susceptible to cold physical plasma-induced apoptosis. Sci. Rep. 2017, 7, 2791. [CrossRef]

49. Gaschler, M.M.; Stockwell, B.R. Lipid peroxidation in cell death. Biochem. Biophys. Res. Commun. 2017, 482, 419-425. [CrossRef] [PubMed]

50. Carvalho, F.S.; Burgeiro, A.; Garcia, R.; Moreno, A.J.; Carvalho, R.A.; Oliveira, P.J. Doxorubicin-induced cardiotoxicity: From bioenergetic failure and cell death to cardiomyopathy. Med. Res. Rev. 2014, 34, 106-135. [CrossRef]

51. Ma, Y.; Ha, C.S.; Hwang, S.W.; Lee, H.J.; Kim, G.C.; Lee, K.W.; Song, K. Non-thermal atmospheric pressure plasma preferentially induces apoptosis in p53-mutated cancer cells by activating ros stress-response pathways. PLoS ONE 2014, 9, e91947. [CrossRef]

52. Sagwal, S.K.; Pasqual-Melo, G.; Bodnar, Y.; Gandhirajan, R.K.; Bekeschus, S. Combination of chemotherapy and physical plasma elicits melanoma cell death via upregulation of slc22a16. Cell Death Dis. 2018, 9, 1179. [CrossRef] [PubMed]

53. Vijayarangan, V.; Delalande, A.; Dozias, S.; Pouvesle, J.M.; Robert, E.; Pichon, C. New insights on molecular internalization and drug delivery following plasma jet exposures. Int. J. Pharm. 2020, 589, 119874. [CrossRef]

54. Liao, Y.C.; Liang, W.G.; Chen, F.W.; Hsu, J.H.; Yang, J.J.; Chang, M.S. Il-19 induces production of il-6 and tnf-alpha and results in cell apoptosis through tnf-alpha. J. Immunol. 2002, 169, 4288-4297. [CrossRef] [PubMed]

55. Sommer, A.; Fabri, M. Vitamin d regulates cytokine patterns secreted by dendritic cells to promote differentiation of il-22producing t cells. PLoS ONE 2015, 10, e0130395. [CrossRef] [PubMed]

56. Hawrylowicz, C.M. Regulatory t cells and il-10 in allergic inflammation. J. Exp. Med. 2005, 202, 1459-1463. [CrossRef]

57. Conlon, K.C.; Miljkovic, M.D.; Waldmann, T.A. Cytokines in the treatment of cancer. J. Interferon Cytokine Res. 2019, 39, 6-21. [CrossRef]

58. Lin, C.F.; Lin, C.M.; Lee, K.Y.; Wu, S.Y.; Feng, P.H.; Chen, K.Y.; Chuang, H.C.; Chen, C.L.; Wang, Y.C.; Tseng, P.C.; et al. Escape from ifn-gamma-dependent immunosurveillance in tumorigenesis. J. Biomed. Sci. 2017, 24, 10. [CrossRef]

59. Vegran, F.; Berger, H.; Boidot, R.; Mignot, G.; Bruchard, M.; Dosset, M.; Chalmin, F.; Rebe, C.; Derangere, V.; Ryffel, B.; et al. The transcription factor irf1 dictates the il-21-dependent anticancer functions of th9 cells. Nat. Immunol. 2014, 15, 758-766. [CrossRef]

60. Senovilla, L.; Vacchelli, E.; Galon, J.; Adjemian, S.; Eggermont, A.; Fridman, W.H.; Sautes-Fridman, C.; Ma, Y.; Tartour, E.; Zitvogel, L.; et al. Trial watch: Prognostic and predictive value of the immune infiltrate in cancer. Oncoimmunology 2012, 1, 1323-1343. [CrossRef] 